\title{
How to study ethnic food: senses, power, and intercultural studies
}

\author{
Defne Karaosmanoğlu(i)
}

\begin{abstract}
This article gives a broad review of the literature focusing on food, senses, and intercultural relations. Integrating cultural studies literature and concepts into ethnic food studies, it tries to understand the ways in which ethnic food becomes an agent of social change and helps to build, promote, and improve intercultural relations. More specifically, this article tries to explore the ways in which ethnic food could be used as a pedagogical tool in intercultural relations. The following questions are explored in anthropology and cultural studies literature: To what extent can ethnic food bring a feeling of connection with other cultures? To what extent can it bring an understanding of others? What kind of a role do the senses of taste and smell play in this process? At least three steps are proposed in the study of ethnic food and intercultural relations: Integrating sensory studies into food studies, applying self-reflexive ethnographic methodologies which are based on experience and emotion, and finally exploring the relationship between food and power, and food and agency.
\end{abstract}

Keywords: Intercultural studies, Food pedagogy, Senses, Reflexivity, Agency

\section{Introduction}

There are numerous studies on ethnic foods which focus on multiple issues. Journal of Ethnic Foods contributes mainly to the growth of knowledge and information about ethnic foods, including their stories, histories, cultures, traditions, recipes, nutritional values, and consumption processes [1]. JEF also acknowledges the role ethnic food plays in modern societies, especially in bringing harmony and peace [1]. In this article, I focus on the consumption of ethnic food and its role in intercultural relations. More specifically, I try to explore the ways in which ethnic food could be used as a pedagogical tool in intercultural relations. Therefore, the following questions are explored in anthropology and cultural studies literature: To what extent can ethnic food bring a feeling of connection with other cultures? To what extent can it bring an understanding of others? What kind of a role do the senses of taste and smell play in this process? To be able to answer these questions, I review the literature in various fields, mainly in anthropology and cultural studies.

Correspondence: defnekar@gmail.com

Faculty of Communication, Kadir Has University, Cibali, 34083 Istanbul, Turkey
Integrating food into the cultural studies literature with a sensory approach enables us to see food as a powerful agent which can shape and re-shape intercultural relations. In this study, first I try to understand the consumption of ethnic food and the phenomenon of "eating the other" in scholarly work. Rather than making general claims, I argue that we need to be radically context dependent as cultural studies have proposed. Secondly, I briefly introduce studies which offer ways to approach taste and smell in social sciences. I then argue for an ethnographic approach in studying food and senses. Lastly, I move to ethnic food studies and explore the relationship between consumption of food, food pedagogy, and power.

\section{Ethnic food and cultural studies}

When we look at the consumption of foreign food, the phenomenon of "eating the other" and its expressions of power and privilege come up very often [2-6]. bell hooks's notion of "eating the other" refers to the ways that ethnicity becomes spice or seasoning for the mainstream white culture [7]. This is very much perceived from a single perspective of power where white consumers

(c) The Author(s). 2020 Open Access This article is licensed under a Creative Commons Attribution 4.0 International License, which permits use, sharing, adaptation, distribution and reproduction in any medium or format, as long as you give appropriate credit to the original author(s) and the source, provide a link to the Creative Commons licence, and indicate if changes were made. The images or other third party material in this article are included in the article's Creative Commons licence, unless indicated otherwise in a credit line to the material. If material is not included in the article's Creative Commons licence and your intended use is not permitted by statutory regulation or exceeds the permitted use, you will need to obtain permission directly from the copyright holder. To view a copy of this licence, visit http://creativecommons.org/licenses/by/4.0/.
} 
are privileged in choosing, colonizing, incorporating, and exploiting the others and their tastes. However, this single perspective of power relations has undergone serious criticisms. According to Peter Jackson, we should "examine more closely the complexities of the production process, the politics of representation and the practices of consumption" to grasp the shifting power relations of each specific case [8]. For example, ethnic food (or ethnic restaurant) becomes a way to produce knowledge about a group of people or region [9]. Therefore, the question is whether the so-called "white consumers" would learn about other cultures and learn to appreciate differences.

Therefore, while commenting upon the consumption of ethnic food, we need to be radically context dependent. After all, consumer groups are not necessarily homogeneous since people have heterogeneous biographies and everyday lives [10-12]. Therefore, we may need to get rid of the perception of a homogeneous group of white consumers. A well-respected cultural studies scholar Lawrence Grossberg proposes the concept of "radical contextualization" as a research strategy [13] where each context produces distinct links, connections, meanings, and discourses: "If reality is relational and articulated, such relations are both contingent (i.e. not necessary) and real, and thus, never finished or closed for all times." As a resistance to Marxist determinism, contextualism is a condensation of multiple determinations, and effects and the linkage are not necessary, determined, absolute, or essential for all time.

Moreover, coming from a Marxist theory, cultural studies extensively explores the relationship between structure and agency. And it has always been careful about the taken-for-granted asymmetrical power relations favoring the structure. Sensory apparatus is also a potential topic for cultural studies, which is unfortunately underexplored for many years in social sciences. The reason for this could be that senses of taste and smell are embodied with memories, and personal and subjective feelings, which make them not only difficult to study, but also illegitimate sources of knowledge.

\section{Studies on senses}

"The sensorium is a fascinating focus for cultural studies," says Walter J. Ong [14]. As a reply to the tendencies of prioritizing and essentializing visuality in social sciences, Zygmunt Bauman argues, "modernity declared war on smells. Scents had no room in the shiny temple of perfect order modernity set out to erect" [15]. Bauman considers smell to be the antithesis of modernity. Similarly, Constance Classen, David Howes, and Anthony Synnott argue in their book Aroma: The Cultural History of Smell that the visual, as the superior, most reliable of the five senses, is a cultural phenomenon worth critical analysis [16]. In the eighteenth and nineteenth centuries, smell was devalued because the philosophers and scientists of that period, according to Classen, Howes, and Synnott, decided that the sight (vision) was the sense of reason and civilization, while smell was the sense of madness and savagery. Smell is marginalized because it is felt to threaten the rational and objective part of modernity [16]. In other words, Western tradition devalues taste (and smell) as a lower sense that does not promote reasoned judgment and that blurs the basic western philosophic divide between "subjective" and "objective" [16].

While modern thinking has been challenged for quite a while, the question of how to analyze and comment upon taste and smell, in other words, how to turn them into knowledge is still undetermined. Only over the last few decades, scholars across social sciences and humanities have turned their attention on the senses and on the question above. In 2018, Bloomsbury published a six-volume series called A Cultural History of Senses edited by Constance Classen and a four-volume series called Senses and Sensations edited by David Howes [17, 18]. While the former series provides a historical approach to the study of senses starting from the antique times to the modern age, the latter explores the ways in which senses are studied in various disciplines from geography, anthropology, history, sociology, and art to biology, psychology, and neuroscience.

On the other hand, academic studies that deal with the intersection of food and senses have been explored comprehensively by David Sutton [19]. As Sutton argues, there are "three potential directions for further ethnographic exploration and analysis:" The first one takes food's sensory qualities as embodied forms of social distinction. Here, we are talking about hegemonic sensory regimes [19]. For example, taste and smell build boundaries between groups, the West and immigrants, which provide a ground to start thinking about food and intercultural studies. According to Paul Rodaway, senses are geographical since they contribute to people's orientation in space and to their awareness of spatial relationships [20]. Therefore, senses play a crucial role in building cultural borders. John Urry argues that smell builds boundaries of gender, class, ethnicity, race, and nationality. Different smells are assigned to different social classes and ethnic groups in the West [21]. Sandra Soo-Jin Lee explores the relationship between kimchee and Korean identity [22]. According to Lee, "Korean food played a crucial role in the practice of Korean identity in Japan," and there is a close association between being Korean and the ability to eat kimchee [22]. Cho, a 72-year-old Korean, is apologetic since he cannot eat kimchee, and he thinks that because he has been living in Japan for so long, his sense of taste has altered. Therefore, the failure of bodily memory in the 
performance of an important cultural practice influences identity performance [22]. According to Lee, "Food choices may be understood as performative and integral to the communication of identity" [22]. Not to be able to eat kimchee is a sign of weakness for Koreans. One trains the body to eat kimchee regularly, not to fall into a rhetoric, moral failure, and cultural inauthenticity [22]. Therefore, eating spicy Korean food reflects the Korean residents' struggles in negotiating their identity in Japanese society. Lee rightly argues that bodily memory is helpful in understanding the struggles for identity, and it "remains a dialectic between objectified knowledge and existential meaning in the struggle for identity" [22]. Here, taste and smell work as an existential and bodily performance in the construction of identity where objective knowledge has no usage.

The second one understands or analyzes society's key flavor principles and oppositions through the combination of different senses perhaps other than those which are familiar to us, such as salty, sweet, sour, and bitter. Synesthetic contributions and intersensoriality are the concepts that are discussed. For example, the ancients (following Aristotle) viewed taste as a form of touch; and we can see in modern period taste is closely connected with smell rather than touch. And according to the latest scientific estimates, there are at least ten senses and possibly as many as thirty-three [23]. Senses cannot be separated from each other. For example, sound or smell may evoke sensations of color.

The third direction takes taste as central to exploring other aspects of culture [19]. Here, perhaps studying transformations in world history by focusing on cultural changes is crucial. Sidney Mintz's famous book Sweetness and Power [24] gives us a comprehensive understanding of political economy of sugar in world history. Mintz studies sugar from a geographical/anthropological and historical perspective. He looks at the power relations between producers and consumers of sugar. He investigates how the British planted sugar cane in the Caribbean and Jamaica. In the seventeenth and eighteenth centuries, 12 million African slaves were brought to the Caribbean and Jamaica to work in the fields. From there, sugar was transported to Europe to be consumed as a luxury food. In Europe, from 1400 to 1650, sugar was considered a luxury commodity; and only after the 1850 s, sugar became a product of mass consumption. According to Mintz, "sugar...has been one of the massive demographic forces in world history" where millions of Africans were brought to the Americas [24].

These three potential directions for further ethnographic analysis may help us to approach senses in multiple ways considering the power relations in either hegemonic sensory regimes, intersensoriality, or political economy. Studying senses, therefore, opens a path to understand power, politics, and global/local transformations. In this study, however, I explore the ways in which senses play a role in breaking cultural borders. I try to understand how hegemonic sensory regimes can be destroyed when the power of senses is acknowledged at personal and interpersonal levels. For that, we need an ethnographic approach which takes our own bodies as sources of knowledge.

Sarah Pink gives us practical guidelines in doing research on the senses with a self-reflexive point of view. The ethnographer's own experience or experiencing the body is crucial here. It is about using the body as a research tool [25]. Senses, after all, are not static, but they are constantly shifting and changing mostly in relation to human perception and practice. And the ethnographer's own sensory experience inevitably shapes the production of knowledge.

Pink suggests two methodological means to be followed in conducting research [25]. One is sensory subjectivity; that is, we need to examine our own sensory subjectivity from both cultural and personal perspectives. We can start with a kind of auto-ethnography and be aware of our own role in the production of ethnographic knowledge. Reflexivity has been an important part of ethnography where the binary of objectivity versus subjectivity is no longer applicable. Especially feminist geographers and anthropologists have embraced reflexivity in their methodologies. As Gillian Rose claims, "researcher, researched and research make each other; research and selves [are] 'interactive texts"' [26]. In this respect, the body should operate as an instrument in research since the research process is affected by "bodily reactions, gestures, physical presence, the smell of bodies, tone of voice" [27]. For example, the geography of disgust is an unspeakable geography, and yet it is very real: "Our feelings made us question our own silences and constructions of Otherness." Research, therefore, is an embodied process [27], and using our body as a research tool is an important part of ethnography.

The second concept is sensory intersubjectivity. Pink considers the importance of "intersubjective relations with others and our material/sensory environments." She argues that our social interactions are not based on verbal communication nor visual impressions, but rather they are multisensory and fully embodied [25]. Therefore, as researchers, we need to approach people not as objects of experiment, but as participants in the project. This is based on a collaborative and participatory approach. Therefore, following Pink, through the approaches of sensory subjectivity and intersubjectivity, our bodies can be used as a research tool while dealing with taste and smell.

Hegemonic sensory regimes and the relationship between senses and social distinction should be further explored. This is exactly where cultural studies should interfere. If we accept the fact that senses of taste and smell build boundaries of ethnicity, class and nationality, 
and that different odors and tastes are assigned to different social classes and ethnic groups, we should consider the potential power of food in intercultural studies, even though this potential is always contingent and context dependent. Figure 1 shows the research concepts needed to study ethnic food.

\section{Ethnic food as an agent of social change in intercultural studies}

There needs to be further exploration on the relationship between ethnic food and power. Some theorists emphasize the cuisine's active role as an agent of social change and a source of empowerment in the global market. For example, Sylvia Ferrero stresses the economic, social and even political power of cultural brokers in the production, circulation, and representation of cuisine and its cultural image in the case of Mexican restaurants in Los Angeles [28]. She looks at Mexican cuisine not only as an expression of social and cultural identity, but also as a space where social change is made possible. She argues that the Mexican restaurant business in Los Angeles opens paths for immigrant labor, empowers the ethnic "I," enhances economic and social power, and establishes solidarity and social alliances among immigrants [28]. As a result, Mexican cuisine is used by Mexican immigrants in Los Angeles to accomplish social and economic improvement. Ayșe Çağlar shows that German Turks have the power to define their own identity in Döner Kebab businesses in Berlin [29]. Lisa Law emphasizes the status of Filipino women in Hong Kong as powerful agents due to their active creation of space in the city through cooking and eating. Filipino women use food to establish relationships among themselves in a foreign land [30]. These studies are significant in the sense that they problematize conventional understandings of power relations and identity politics within the marketplace. Moreover, cuisine and culinary practices play an active role in providing cultural spaces for political processes. Kebab has served to lower hostilities against foreigners and Turks in particular. The slogan used against German racism was "No döner without the foreigners." For Çağlar, kebab as a means of building communication is used to establish solidarity, not only among the Turks but also between Turks and other foreigners [29]. Moreover, in Carol M. Counihan's study, food was seen as a vehicle for speaking about gender, class, and ethnic barriers in the San Luis Valley of Colorado [31]. Gamal Abdel-Shehid shows the role of new soul food in the fight against racism [32].

Therefore, rather than simply reducing both individual entrepreneurs and consumers to passive and powerless objects, we should consider the role they play in processes of self-identification, establishing solidarity and minimizing hostilities and racism. Here, the concepts of food pedagogy and public pedagogy become useful. Rick Flowers and Elaine Swan define public pedagogy as "the sites, processes and technologies of learning that happen outside of formal educational systems" [33]. Food can be used as a tool for public pedagogy in everyday life. For instance, by eating ethnic food, one can learn about different cultures. Lisa Stowe and Dawn Johnson argue that sensory learning is an important component of culinary tourism [34].

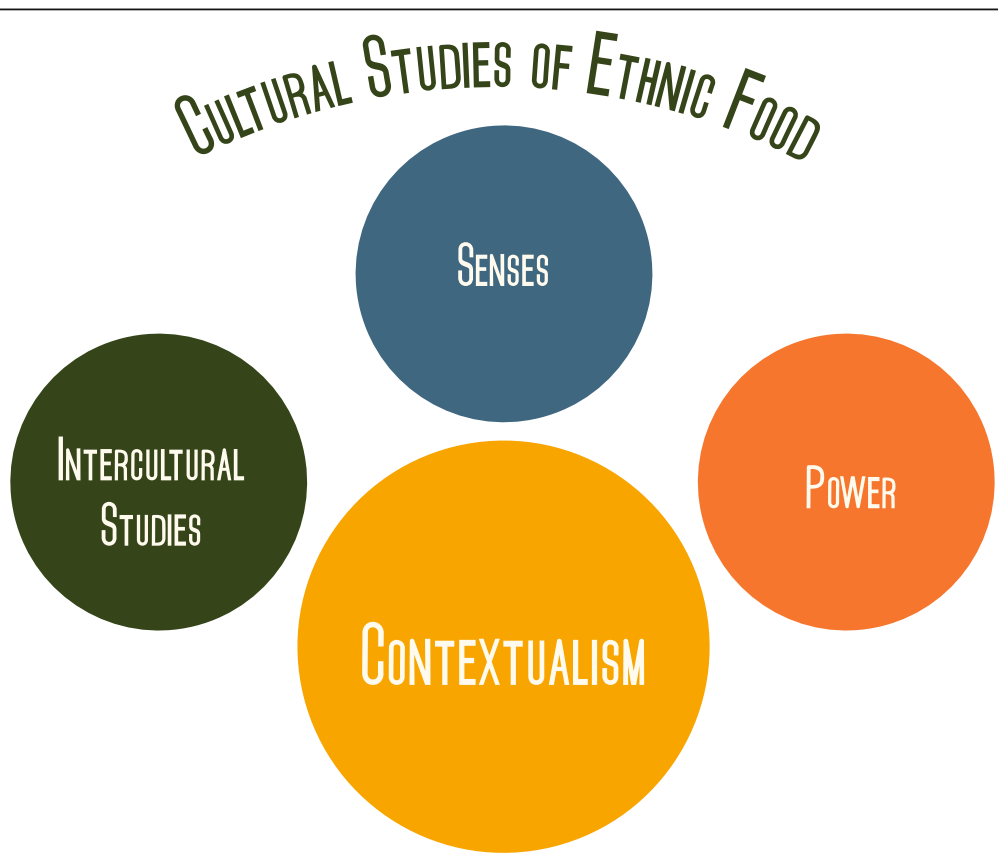

Fig. 1 The research concepts needed to study ethnic food 
Ben Highmore, a cultural studies scholar, explores the relationship between taste, xenophobia, and multiculturalism [35]. Turning the notion of eating the other upside down, he asks whether taste can minimize xenophobia and racism, and at the same time, bring closeness and understanding of "the Other." He specifically looks at white British working-class football fans. Highmore claims that eating curry is a marker of working-class machismo since "going for a curry" is an expression used by white English men especially after drinking in pubs. Vindaloo (an Indian curry dish popular in Goa), on the other hand, is England's unofficial football anthem. Vindaloo is chosen since it sounds similar to Waterloo where Napoleon was defeated in 1815 and which has become a symbol of Englishness. Therefore, a nationalistic tone can also be heard in Vindaloo which has also become an ironic marker of Englishness. We see a crowd of English football supporters, waving the St. George flag and chanting "Vindaloo", but does this make them more welcoming and less xenophobe? The common comment would be that white British people eat vast amounts of curry, but they are not welcoming towards the Asians who make it for them. This is seen as part of colonialism, where English football supporters appropriate a dish Indians make, which means colonizing both Indians and their dishes. In other words, ethnicity has become a spice as bell hooks famously put, and the English colonists colonize the people, culture, and their food.

However, this common perception for Highmore is not enough to understand the complexity of the situation. What is left unexplored according to him is that eating curry might include a "pedagogic function that would alter the aggressive and xenophobic contact with both a food culture and a social culture" [35]. The Englishman asks for the hottest dish on the menu. The chilies make him sweat, inflicting pain on his tongue and mouth. The eater has finished but the chilies are not finished with him. It is still continuing its alimentary journey [35]:

Has the chili reconfigured the man's sensual orchestration, opening him up to the pleasures and pain of chili... The multicultural scene that is being conducted is not simply of hearts and minds, but of guts too. And it is here where thinking about food consumption in relation to the psycho-social material subject can play a significant role.

If "disgust works to protect and re-affirm the boundaries of the cultural self" and if it builds boundaries between the self and the other and brings hatred, racism, and fear, then sensual relish can do the opposite, which is to break boundaries, and make the self more open to others [35]. Therefore, curry might educate the English xenophobe and make him be more emphatic. This type of sensual pleasure or appreciation might be stronger than intellectual understanding. According to Highmore, "Taste and smell play an inexorable role in everyday forms of racism. Yet they are also central components for convivial and cosmopolitan intercultural, inter-ethnic exchange" [35]. We need to remember Uma Narayan, who builds the basis of Highmore's argument. For Narayan, pleasures of taste provide more powerful bonds than knowledge. This is fundamental in countering the physical alienation between ethnic communities and in fostering "thick" multiculturalism $[35,36]$. Highmore calls for a new approach in intercultural studies, which he calls "social aesthetic approach to intercultural food exchange." This is an approach that brings together sociological elements with new approaches to the senses [35]. Highmore defines social esthetics as the "re-orchestrations of aesthetic life, in cities and towns, where significant alterations to the "sensescape" have taken place" [35].

The esthetic is not divorced from political analysis. As Highmore argues, "smell and taste are incidental ingredients in a series of cultural scenes that need to be explained by recourse to the 'harder stuff' of political and sociological discourse" [35]. Food spaces can provide a means to encounter the others and in these potential spaces of encounter, affective experience, and feelings, such as joy, aggression, hate, fear, and love, are negotiated which might open a way to accept and understand the other [35].

The material agency of food itself plays its part. For example, the taste of fresh coriander will train an unfamiliar palate to like it. Highmore's own experience with coriander is interesting at the personal level. When he first tasted coriander, he did not like it. Then, after a period of time, when he had been exposed to coriander, he has developed a taste for it and started to like it. In fact, he started to like it a lot. He said he could taste different tastes in the food he is eating, so coriander has actually changed his taste buds:

Who is the agent of transformation here? Have I altered coriander in some way? Or, as I would argue, has the coriander, as an agent, worked on me, taught my taste buds to recognise the subtle fragrant flavours of coriander, to hear its complex notes? [35]

In this case, food, taste, and smell move from being passive tools in research to active agents of social change at the intercultural level.

\section{Conclusion}

The ultimate aim of this study is to demonstrate how ethnic food can become an agent of social transformation in intercultural encounters. While taking 
contextualism, senses, and power into account, cultural studies provide us with the necessary tools to approach ethnic food. Combining contextualism, the sensory approach, and agency, I have explored the ways in which ethnic food becomes an agent of social change and helps to build, promote, and improve intercultural relations. Here, food pedagogy emerges as an important concept.

In this study, I argue that while studying with and around food, we should be radically context dependent and should take senses together with subjectivity and intersubjectivity into account.

Therefore, we should follow at least three steps in the study of ethnic food and intercultural relations. First, we need to integrate sensory studies into food studies. There is a considerable number of studies dealing with intercultural studies and food. However, there are few studies that consider the role and transforming potential of taste and smell in intercultural relations. We need to find methodological ways to include the senses of taste and smell in ethnic food studies; that is, we need to find ways to approach ethnic food including, and therefore not neglecting the senses of smell and taste.

Secondly, in ethnic food studies, we need to apply selfreflexive ethnographic methodologies which are based on experience and emotion. We should be able to look at the culturally shaped senses and sensory experiences of food in multiple contexts, and how they are invested with meaning, emotion, memory, and value [19]. Therefore, while being radically context dependent, we may try to understand others' experiences of taste and smell as well as our own. Therefore, we use our body as a research tool both to understand the senses of others and thereof our own. Here, we need to think about self-reflexivity together with Pink's notions of subjectivity and intersubjectivity [25]. Pink does not study the senses as the sole and primary object of study. But it may become part of a methodology, part of an approach to understand other people's experiences, ways of life, and values.

Third, we definitely need to explore the relationship between food and power; and food and agency. Food can also be a powerful agent of social change. Food is not just a simple object to be consumed, but it is something that triggers disgust and relish at the same time. It is perhaps the only mundane commodity that cannot be approached without considering the sensory apparatus. Emotions and senses have the power to change individual perception. They can even change the way we see the world around us. They can change the way we see others around us. They can change the way we see ourselves. They can change the way we see change itself. The power of ethnic food may be magical in this regard. Its power especially in intercultural studies should be explored further. In Fig. 2, the methodological model summarizing the arguments of this paper is presented.

Food is recently used in various fields such as public relations and public diplomacy. These studies assert that food has the potential to change the public perception of a nation's image [37]. This is why gastrodiplomacy which emphasizes the power of food and flavors in changing public perception of a country emerges as a useful

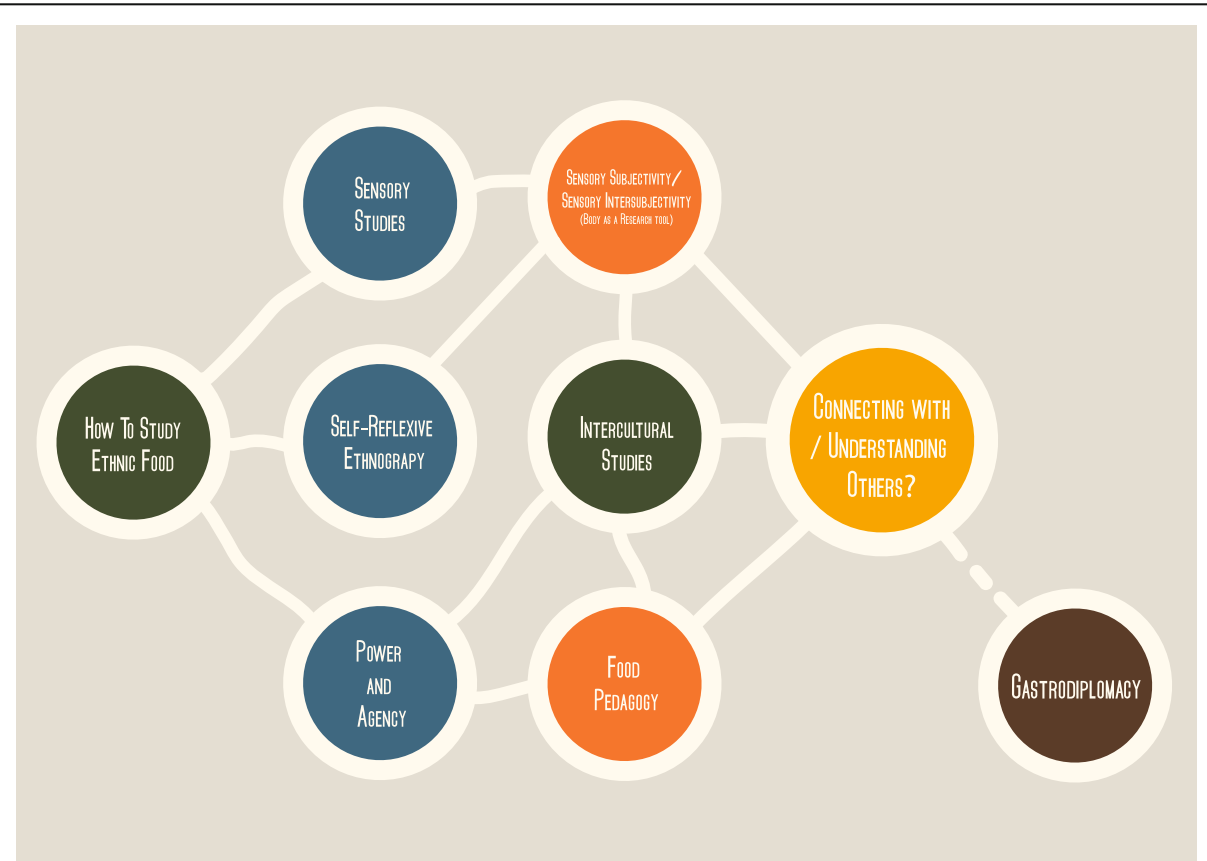

Fig. 2 Methodological model summarizing the arguments of this paper 
concept. However, studies on gastrodiplomacy do not really intersect with the sensory approach and cultural studies. They are usually developed under the field of public relations and with concepts such as diplomacy and nation branding. What we may need for future studies is a wholistic approach which combines gastrodiplomacy, sensory regimes, food pedagogy, and intercultural studies (see Fig. 2).

Finally, this study has searched for various theoretical and methodological ways to study the intersection between ethnic food, senses, and power. It encourages the production of further academic approaches to food studies without neglecting the senses and power relations. Therefore, we need further academic research on sensory studies of ethnic food and its potential power to change intercultural relations.

\section{Acknowledgements}

I would like to thank Güneş Resul for her valuable comments as well as her generous contribution to the design of the diagrams.

\section{Author's contributions}

Not applicable. The author read and approved the final manuscript.

\section{Author's information}

Defne Karaosmanoğlu received her Ph.D. in Communication Studies from McGill University. Her articles are published in the International Journal of Cultural Studies; Food, Culture and Society; Space and Culture; and the Journal of Intercultural Studies. Her research interests include cultural studies of food, discourse and identity, political communication, and nation branding. She is currently teaching in the Faculty of Communication at Kadir Has University, Istanbul.

\section{Funding}

There is no funding.

\section{Availability of data and materials \\ Not applicable}

\section{Competing interests}

There are no competing interests.

Received: 28 December 2019 Accepted: 27 April 2020

Published online: 04 May 2020

\section{References}

1. Kwon DY. What is ethnic food? J. Ethn. Foods. 2015;2(1):1.

2. Cook I, Crang P, Thorpe M. Eating into Britishness: multicultural imaginaries and the identity politics of food. In: Roseneil S, Seymour J, editors. Practising identities: power and resistance. London: Macmillan; 1999. p. 223-48.

3. Hage G. At home in the entrails of the West. In: Grace H, Hage G, Johnson L, Langsworth JK, Symonds M, editors. Home/world: space, community and marginality in Sydney's west. Annandale: Pluto Press; 1997. p. 99-153.

4. Heldke L. Exotic appetites. New York: Routledge; 2003.

5. May J. A little taste of something more exotic: the imaginative geographies of everyday life. Geography. 1996;1:57-64.

6. Molz JG. Eating difference: the cosmopolitan mobilities of culinary tourism. Space and Culture. 2007;10:77-93.

7. hooks b. Eating the other: desire and resistance. In: Scapp R, Seitz B, editors Eating culture. Albany: State of University of New York Press; 1998. p. 181-200.

8. Jackson P. Commercial cultures: transcending the cultural and the economic. Progress in Human Geography. 2002;1:3-18.

9. Gaytán MS. From Sombreros to Sincronizadas: authenticity, ethnicity, and the Mexican restaurant industry. J. Contemp. Ethnogr. 2008;37(3):314-41.

10. Cook I. Geographies of food: mixing. Progress in Human Geography. 2008;6: 821-33.
11. Duruz J. Eating at the borders: culinary journeys. Environment and Planning D: Society and Space. 2005;23:51-69.

12. Duruz J. Floating food: eating Asia in kitchens of the diaspora. Emotion, Space and Society. 2010:3:45-9.

13. Grossberg L. Cultural studies in the future tense. Durham: Duke University Press; 2010.

14. Ong WJ. The shifting sensorium. In: Howes D, editor. The varieties of sensory experience: a sourcebook in the anthropology of the senses. Toronto: University of Toronto Press; 1991. p. 25-30.

15. Bauman Z. The sweet smell of decomposition. In: Rojek C, Turner BS, editors. Forget Baudrillard? London: Routledge; 1993. p. 22-46.

16. Classen C, Howes D, Synnott A. Aroma: the cultural history of smell. London: Routledge; 1994

17. Classen C, editor. A cultural history of the senses (six volume). London: Bloomsbury; 2018

18. Howes D, editor. Senses and sensations (four volumes). London: Bloomsbury; 2018.

19. Sutton D. Food and the senses. Annu. Rev. Anthropol. 2010;39:209-23.

20. Rodaway P. Sensuous geographies. London: Routledge; 1994.

21. Urry J. Sociology beyond societies: mobilities for the twenty-first century. London: Routledge; 2000.

22. Lee SS. Dys-appearing tongues and bodily memories: the aging of firstgeneration resident Koreans in japan. Ethos. 2000;28(2):198-223.

23. Howes D, editor. The sixth sense reader. Oxford: Berg; 2009.

24. Mintz SW. Sweetness and power: the place of sugar in modern history. New York: Viking: 1985

25. Pink S. Doing sensory ethnography. London: Sage; 2009.

26. Rose G. Situating knowledges: positionality, reflexivities and other tactics. Progress in Human Geography. 1997;21(3):305-20.

27. Longhurst R, Ho E, Johnston L. Using 'the body' as an 'instrument of research': kimch'i and pavlova. Area. 2008:40(2):208-17.

28. Ferrero S. Comida sin par. Consumption of Mexican food in Los Angeles: foodscapes in a transnational consumer society. In: Belasco W, Scranton P, editors. Food nations: selling taste in consumer societies. New York: Routledge: 2002. p. 194-220

29. Caglar A. Mc Kebap: Döner Kebap and the social positioning struggle of German Turks. In: Lentz C, editor. Changing food habits: case studies from Africa, South America and Europe. Amsterdam: Harwood Academic Publishers; 1999. p. 263-84.

30. Law L. Homecooking: Filipino women and geographies of the senses in Hong Kong. Ecumene: A Journal of Cultural Geographies. 2001;8(3):264-83.

31. Counihan CM. Food as women's voice in the San Luis Valley of Colorado. In: Counihan CM, editor. Food in the USA: A Reader. New York: Routledge; 2002. p. 295-304.

32. Abdel-Shehid G. Cultural globalization and the soul food memoir: Austin Clarke, Ntozake Shange and Marlon Riggs. J. Hist. Sociol. 2002:15(4):451-64.

33. Flowers R, Swan E. Eating the asian other? Pedagogies of food multiculturalism in australia. PORTAL Journal of Multidisciplinary International Studies. 2012;9(2):2-30.

34. Stowe $L$, Johnson D. Throw your napkin on the floor: authenticity, culinary tourism, and a pedagogy of the senses. Aust. J. Adult Learn. 2012;52(3):460-83.

35. Highmore B. Alimentary agents: food, cultural theory and multiculturalism. J Intercult Stud. 2008:29(4):381-98.

36. Narayan U. Eating cultures: incorporation, identity and indian food. Social Identities. 1995:1(1):63-86.

37. Ruddy B. Hearts, minds, and stomachs: gastrodiplomacy and the potential of national cuisine in changing public perceptions of national image. Public Diplomacy Magazine. 2014;11:27-33.

\section{Publisher's Note}

Springer Nature remains neutral with regard to jurisdictional claims in published maps and institutional affiliations. 